\title{
Occupational exposure to coal and risk of multiple health outcomes:
}

\section{A case report}

\author{
Zina Hakim ${ }^{1}$, Nada Kotti ${ }^{1}$, Khaoula Ben Younes ${ }^{1}$, Feriel Dhouib ${ }^{1}$, Kaouthar Jmal
}

Hammami $^{1}$, Hamida Turki ${ }^{1}$, Mohamed Larbi Masmoudi ${ }^{1}$, and Mounira Hajjaji ${ }^{1}$

${ }^{1}$ Hedi Chaker Hospital

March 1, 2022

\begin{abstract}
Occupational cutaneous squamous-cell carcinoma has an increased incidence, but rarely suspected. When located in an uncovered skin area, it is closely linked to polycyclic aromatic hydrocarbons exposure. However, single pulmonary anthracosis nodule is rarely described in the literature. The association of both diseases due to the same exposure remains uncommon.
\end{abstract}

\section{Hosted file}

Case Report ZINA CCR.docx available at https://authorea.com/users/462974/articles/558227occupational-exposure-to-coal-and-risk-of-multiple-health-outcomes-a-case-report 


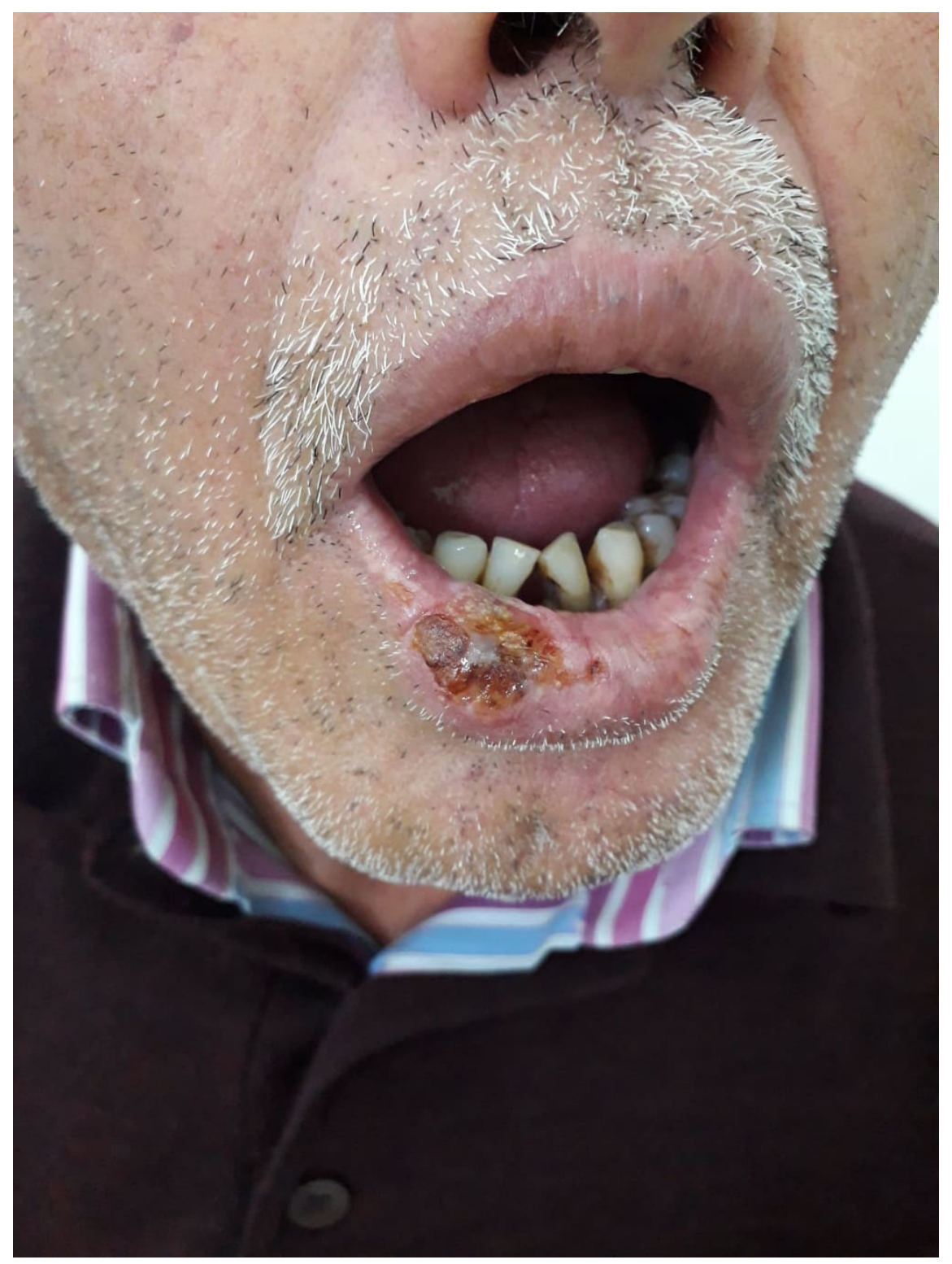

